\title{
AVALIAÇÃO DA DIVERSIDADE DE BORBOLETAS FRUGÍVORAS EM DUAS ÁREAS DE UM FRAGMENTO FLORESTAL NO MUNICÍPIO DE SOLEDADE/RS
}

\author{
Letícia Hoehne ${ }^{1}$, Lisete Maria Lorini ${ }^{2}$, Caroline da Silva Ribeiro ${ }^{3}$
}

\begin{abstract}
Resumo: Com a crescente destruição de hábitat nos diversos biomas, os fragmentos florestais hoje, são essenciais refúgios para a vida silvestre e a manutenção da biodiversidade. O presente estudo tem como objetivos inventariar as diferentes espécies de lepidópteros frugívoros presentes em distintas áreas de um fragmento florestal na zona rural do município de Soledade, Rio Grande do Sul, e comparar a influência da composição dos dois ambientes amostrados na riqueza e diversidade de espécies de borboletas. As amostragens foram realizadas durante quinze dias no mês de janeiro de 2014, em duas áreas: área de regeneração e área de mata ciliar. Em cada área foram posicionadas três armadilhas atrativas fermentadas com banana e açúcar. Após um total de 360 horas de esforço amostral registrou-se 193 capturas de borboletas frugívoras, sendo 68 na área de regeneração e 125 na área de mata ciliar, sendo identificadas 15 espécies de lepidópteros, todos da família Nymphalidae e subfamílias Biblidinae (33\%), Charaxinae (20\%), Morphinae (13\%) e Satyrinae (33\%). Com o estudo foi possível verificar que as borboletas são bioindicadoras da qualidade ambiental, ocorrendo com maior riqueza e diversidade em ambientes melhores conservados, assim como é possível destacar a capacidade de regeneração de ambientes naturais.
\end{abstract}

Palavras-chave: Biodiversidade. Bioindicador. Nymphalidae.

1 Graduação em Ciências Biológicas LicenciaturaPlenapela Universidade de Passo Fundo, Especialização em Biologia da Conversação da Natureza pela Universidade de Passo Fundo, Especialização em Educação Ambiental pelo Centro Universitário Barão de Mauá, São Paulo. Professora de Ciências na Escola Estadual de Ensino Fundamental Justino Alberto Tietboehl, no município de Torres/RS.

2 Graduação em Ciências Biológicas Licenciatura Plena pela Universidade de Santa Cruz do Sul, especialização em Biologia Geral, mestrado em Biociências (Zoologia) pela Pontifícia Universidade Católica do Rio Grande do Sul e doutorado em Ciências Biológicas (Entomologia) pela Universidade Federal do Paraná (2005). Atualmente é professora titular e pesquisadora da Universidade de Passo Fundo. Atua principalmente nos seguintes temas: Biologia de Lonomia obliqua (taturana), comportamento ecológico e flutuação populacional. Lepidópteros de importância médica.

3 Acadêmica do Curso de Ciências Biológicas Bacharelado na Universidade de Passo Fundo e bolsista PAIDEX no Laboratório de Entomologia da Universidade de Passo Fundo. 


\title{
EVALUATION OFTHE DIVERSITY OF FRUGIVOROUS BUTTERFLIES INTWO AREAS OF A FOREST FRAGMENT INTHE MUNICIPALITY OF SOLEDADE/ RS
}

\begin{abstract}
With the increasing destruction of habitats in the various biomes, forest fragments today are essential refuges for wildlife and maintaining biodiversity. The present study aims to inventory the different species of frugivorous lepidopterans present in different areas of a forest fragment in the rural area of the municipality of Soledade, Rio Grande do Sul, and to compare the influence of the composition of the two environments sampled on the richness and diversity of species Of butterflies. The samplings were carried out during fifteen days in January 2014, in two areas: regeneration area and riparian forest area. In each area were placed three attractive traps fermented with banana and sugar. After a total of 360 hours of sampling effort, 193 captures of frugivorous butterflies were recorded, of which 68 were in the regeneration area and 125 in the riparian forest area, 15 species of Lepidoptera were identified, all of the Nymphalidae family and Biblidinae subfamilies (33\%). , Charaxinae (20\%), Morphinae (13\%) and Satyrinae (33\%). With the study it was possible to verify that the butterflies are bioindicators of the environmental quality, occurring with greater richness and diversity in better preserved environments, as well as it is possible to emphasize the regeneration capacity of natural environments.
\end{abstract}

Keywords: Biodiversity. Bioindicator. Nymphalidae.

\section{INTRODUÇÃO}

A área de Mata Atlântica no Brasil compreendia uma extensão de 1.300 .000 km², o equivalente a $12 \%$ do território nacional, por 17 estados, desde o Rio Grande do Norte até o Rio Grande do Sul (PETTIROSSI, 2009). Atualmente restam menos de 7\% de sua formação original, ou seja, menos de $91.000 \mathrm{~km}^{2}$ e está dividida em fragmentos isolados por uma paisagem altamente modificada ou degradada, funcionando como "ilhas de habitat" em uma matriz inóspita dominada pelo homem (PRIMACK; RODRIGUES, 2001).

Muitas vezes os fragmentos florestais são apontados como condicionantes ao isolamento genético, com a consequente perda da diversidade biológica. No entanto, os fragmentos florestais hoje, são essenciais refúgios para a vida silvestre. Viana e Pinheiro (1998) constatam com seus estudos que a maior parte da biodiversidade se encontra em pequenos fragmentos florestais, pouco estudados e historicamente marginalizados pelas iniciativas conservacionistas. Também, Silva et al., (2012), salientam que a diversidade biológica não está homogeneamente distribuída pelo planeta, e o entendimento dos padrões de distribuição dos organismos é essencial para a tomada de decisões corretas visando à conservação. Frente a isso, ressalta-se a importância de conhecer as espécies que habitam os fragmentos florestais, como cita Dajoz (2005), relatando que o desconhecimento da biologia de certas espécies torna sua conservação difícil.

Sendo assim, um dos grupos animais mais numerosos e espacialmente bem distribuídos são os artrópodes, com destaque para os insetos, pois correspondem a quase $60 \%$ de todos os animais do planeta (SILVA et al., 2012). Soares, Oliveira e 
Silva et al. (2012) relatam que o uso de alguns grupos de insetos como indicadores biológicos, tem sido útil devido a sua grande diversidade e abundância, facilidade de amostragem e rápidas respostas a alterações ambientais.

Como integrantes dos insetos, a ordem Lepidoptera, cujo nome provém dos radicais gregos lepido, "escama" e ptero, "asa", possui uma representatividade expressiva nos ecossistemas terrestres (TRIPLEHORN; JOHNSON, 2011), constituindo a segunda maior ordem da classe Insecta (FONSECA et al., 2006), com 124 famílias (FREITAS; MARINI-FILHO, 2011) e mais de 400.000 espécies descritas, sendo 26.000 espécies no Brasil (RAFAEL et al., 2012). No Rio Grande do Sul, de acordo com Bellaver (2012, apud MORAIS et al., 2007) são registradas 769 espécies de borboletas.

As borboletas e as mariposas são insetos holometábolos, em geral mastigadores de material vegetal no estágio larval e sugadores de líquidos (néctar, seiva, água enriquecida, material orgânico em putrefação) na fase adulta (PETTIROSSI, 2009). Estas, de acordo com a dieta alimentar na fase adulta, podem ser divididas em duas guildas: nectarívoras e frugívoras.

As borboletas nectarívoras pertencem às famílias Papilionidae, Pieridae, Lycaenidae, Hesperiidae, Riodinidae e algumas subfamílias de Nymphalidae (que inclui algumas espécies de Ithomiinae, Cyrestini, Apaturinae e Limenitidinae que são eventualmente capturadas com iscas fermentadas). As borboletas da guilda das frugívoras são representadas principalmente por espécies da família Nymphalidae, subfamílias: Satyrinae, Brassolinae, Morphinae, Charaxinae, Biblidinae e pela tribo Coeini (Nymphalinae) (UEHARA-PRADO, 2003).

Em decorrência da interação com plantas frugívoras, a facilidade de amostragem, a taxonomia e sistemática bem definida, o tamanho relativamente grande dos indivíduos e as cores atraentes, tornam as borboletas frugívoras, boas indicadoras da qualidade ambiental. Furlanetti (2010) ressalta que as borboletas frugívoras são bioindicadoras importantes por demonstrarem uma associação estreita com a abundância de plantas hospedeiras, microclima e padrões de disponibilidade de recursos, além de uma grande associação com a estrutura e composição da vegetação.

\section{2 ÁREA DE ESTUDO}

O estudo foi realizado no município de Soledade, o qual possui uma área de $1.213,41 \mathrm{~km}^{2}$ e está localizado na região noroeste do Rio Grande do Sul, no Planalto Riograndense, no alto da Serra do Butucaraí, estando a uma altitude de 726 metros em relação ao nível do mar (PAM, 2008).

O clima do município é considerado subtropical, com as estações do ano bem definidas, com invernos rigorosos, inclusive com ocorrência esporádica de neve, e 
verões quentes. As chuvas são regulares, apresentando maior altura pluviométrica nos meses de julho, agosto e setembro (PAM, 2008).

O solo da região do Planalto Médio provém da formação Serra Geral, e ocorre o predomínio de rochas basálticas, apresentando pouco arenito. No município de Soledade, o solo é do tipo argissolo vermelho-amarelo alumínico associado com neossolo litólico distrófico (PAM, 2008).

Soledade se situa em um encrave de campo na região de ocorrência da Floresta Ombrófila Mista, conhecido como "Campos de Soledade", a vegetação predominante é Estepe Gramíneo Lenhosa. A região de Soledade está inserida na Bacia Hidrográfica do Guaíba, a qual apresenta subdivisões, dentre estas, Soledade aparece como marco divisório entre duas Bacias Hidrográficas: Taquari-Antas (40\% do território municipal) e Alto do Jacuí (60\% do território municipal) (PAM, 2008).

A localidade de Espraiado encontra-se na zona rural do município de Soledade, distante $15 \mathrm{~km}$ do centro da cidade. A área de estudo (FIGURA 1), localiza-se em uma propriedade particular, com aproximadamente $10.000 \mathrm{~m}^{2}$, está a uma latitude $29^{\circ} 03^{\prime} 14^{\prime \prime}$ sul e a uma longitude 51\%26’00" oeste. Nesta área ocorre o encontro do Rio Goes (afluente), com o Rio Espraiado, o qual é o principal rio que abastece o município em questão.

Figura 1 - Mapa de localização do município de Soledade, no Estado do Rio Grande Sul, e imagem de satélite da área de estudo. Na imagem de satélite, o ponto 1 aponta a área de mata ciliar e o ponto 2 a área de regeneração

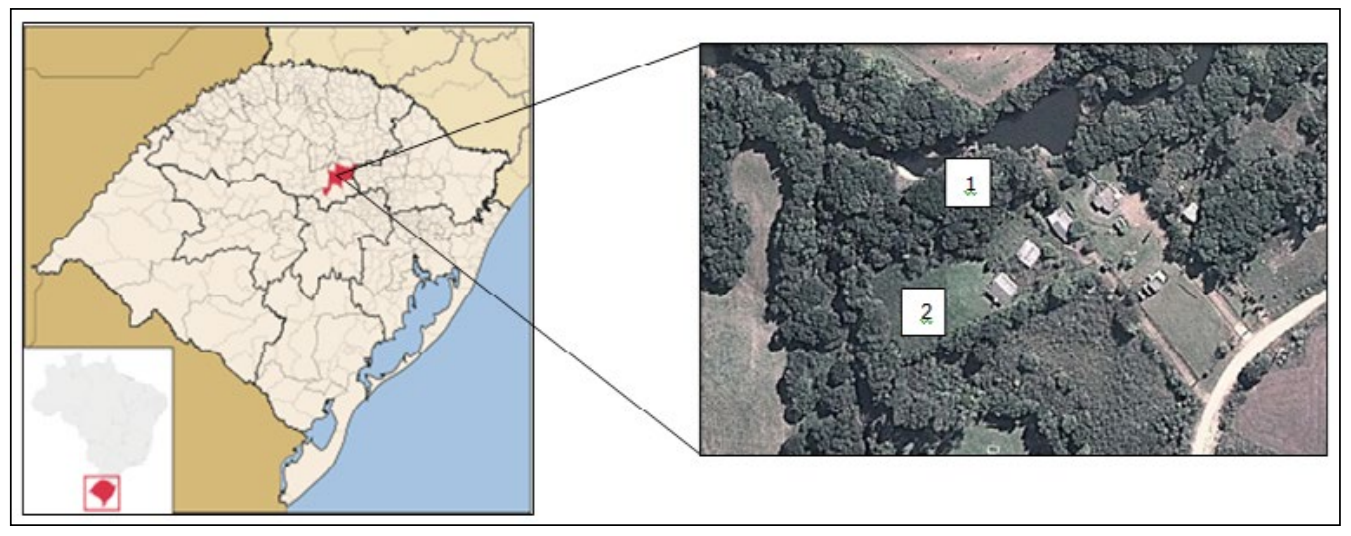

Fonte: www.wikipedia.com.br e www.maps.google.br.

A mata ciliar que fica às margens dos recursos hídricos deste fragmento florestal é bem conservada, promovendo a proteção dos recursos hídricos, da fauna e flora locais, servindo como barreira contra erosão do solo e promove a qualidade e volume da água, mantém a diversidade biológica, além de atuar como corredor ecológico para animais silvestres (WWF, 2014). 
A área de regeneração natural era ocupada por lavoura para consumo familiar, mas devido ao abandono do plantio há cinco anos, a área está se regenerando naturalmente. Conforme Volken (2011), o estudo da regeneração natural permite a realização de previsões sobre o comportamento e desenvolvimento futuro da floresta, pois fornece a relação e a quantidade de espécies que constituem o seu estoque, bem como suas dimensões e distribuição na área. No local, entretanto, existe perturbação antrópica decorrente da prática da pesca.

Nesse ínterim, o presente estudo tem como objetivos inventariar as diferentes espécies de lepidópteros frugívoros presentes nas distintas áreas do referido fragmento florestal, e comparar a influência da composição dos dois ambientes amostrados na riqueza e diversidade de espécies de borboletas.

\section{MATERIAL E MÉTODOS}

Este estudo foi desenvolvido na segunda quinzena de janeiro de 2014 e acompanhado durante 15 dias consecutivos. Deu-se preferência pelo verão, por ser o período do ano com maior atividade reprodutiva e ocorrência dos lepidópteros adultos na natureza.

Dentro da área de estudo foram selecionados dois fragmentos: mata ciliar e mata em regeneração. Em cada fragmento foram instaladas três armadilhas iscadas com bananas fermentadas com açúcar, preparadas com 72 horas de antecedência e substituídas quando necessário. As armadilhas, separadas umas das outras por 10 metros, ficaram dispostas a sul da jusante do rio Espraiado. $\mathrm{Na}$ mata ciliar, as armadilhas foram dispostas em paralelo à margem esquerda do rio Espraiado, e as da área de regeneração foram posicionadas na perpendicular à margem esquerda do mesmo rio, estando em paralelo com o Rio Goes, conforme Figura 2. 
Figura 2 - Esquema da distribuição das armadilhas na área de estudo

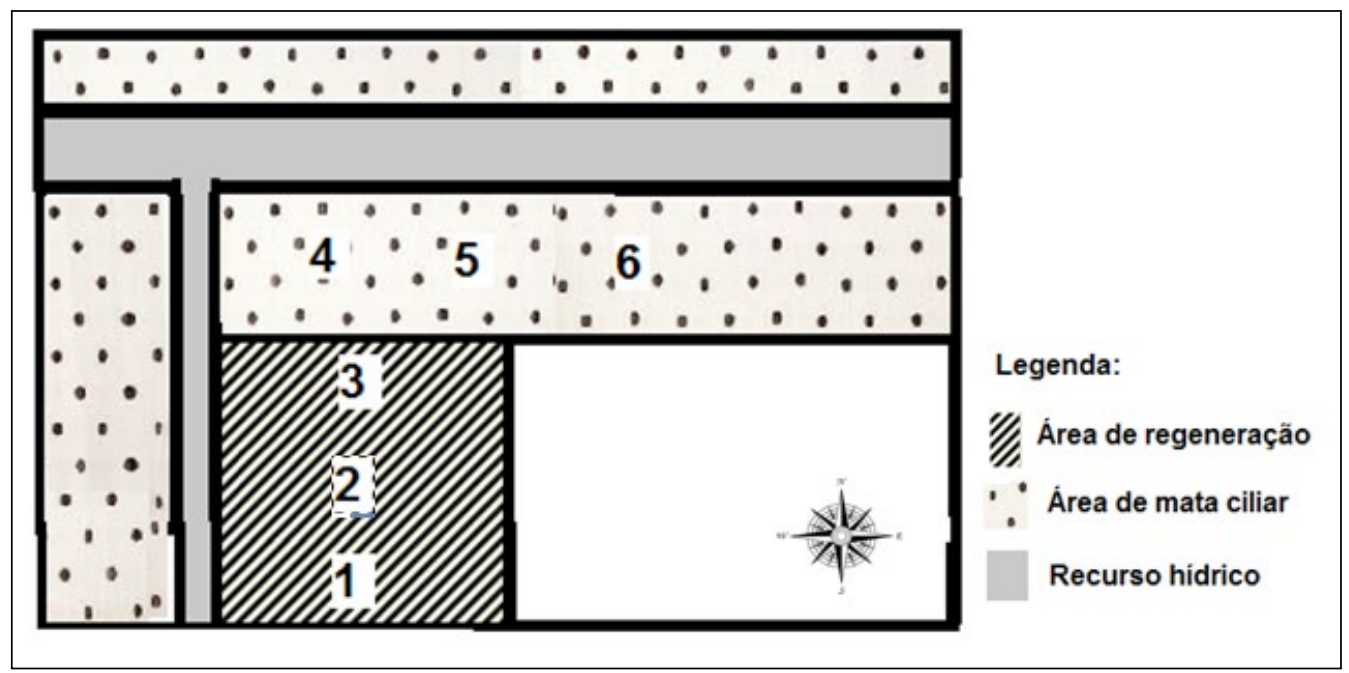

Fonte: dos autores.

Utilizou-se armadilha do modelo Van Someren-Rydon Ribeiro (2006), a qual apresenta formato cilíndrico, envolta por tecido de voal com $1 \mathrm{~m}$ de altura, estruturada por dois aros metálicos, ambos com $30 \mathrm{~cm}$ de diâmetro. A extremidade superior permaneceu fechada e a inferior aberta, onde se colocou a isca.

As armadilhas foram instaladas com a sua base a uma altura de 1,5 metros do chão, utilizando-se uma corda para sustentá-la em galhos mais baixos. A vegetação no local manteve-se preservada durante todo o estudo.

Nas avaliações diárias das armadilhas, os indivíduos capturados foram retirados cuidadosamente, fotografados e, na sequência, liberados no mesmo local. Não foi possível a realização de marcação dos indivíduos capturados pela fragilidade da estrutura corporal dos mesmos.

\section{RESULTADOS}

Em 360 horas de esforço amostral obteve-se 193 capturas de borboletas frugívoras, sendo 125 na área de mata ciliar e 68 na área de regeneração. Nas 193 capturas, identificou-se 15 espécies de lepidópteros, todos da família Nymphalidae e subfamílias Biblidinae (33\%), Charaxinae (20\%), Morphinae (13\%) e Satyrinae (33\%), conforme Tabela 1 e Figura 3. 
Tabela 1 - Distribuição das 15 espécies de borboletas frugívoras da família Nymphalidae nas quatro subfamílias: Biblidinae, Charaxinae, Morphinae e Satyrinae, identificadas no período deste estudo

\begin{tabular}{l|l}
\hline Subfamília & Espécie \\
\hline Biblidinae & Hamadryas februa (Hübner, [1823]) \\
& Hamadryas fornax fornax (Hübner, [1823]) \\
& Biblis hyperia nectanabis (Fruhstorfer, 1909) \\
& Diaethria clymena meridionalis (H. Bates, 1864) \\
& Eunica margarita (Godart, [1824]) \\
\hline Charaxinae & $\begin{array}{l}\text { Archaeoprepona chalciope (Hübner, [1823]) } \\
\text { Memphis moruus stheno (Prittwitz, 1865) }\end{array}$ \\
\hline Morphinae & Zaretis strigosus (Gmelin 1790) \\
\hline Satyrinae & Morpho epistrophus catenaria Perry, 1811 \\
& $\begin{array}{l}\text { Capronnieria achillides C. Felder \& R. Felder, 1867 } \\
\text { Taydebis peculiaris (Butler, 1874) }\end{array}$ \\
\hline & Forsterinaria quantius (Godart, [1824]) \\
& Eteona tisiphone (Boisduval, 1836) \\
Blepolenis catharinae (Stichel, 1902)
\end{tabular}

Fonte: dos autores.

Figura 3 Distribuição dos indivíduos capturados por subfamílias da família Nymphalidae

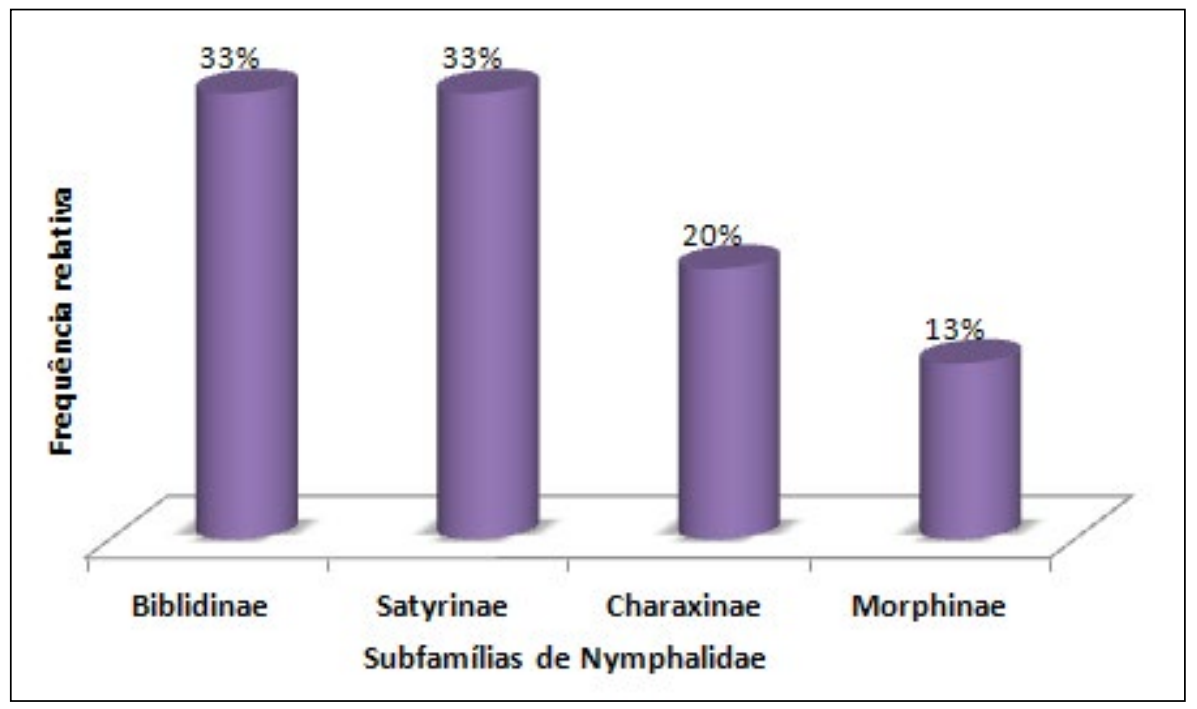

Fonte: dos autores. 
As espécies mais frequentes, em ambas as áreas, foram Taydebis peculiaris (Butler, 1874) e Capronnieria galesus (Godart, [1824]) com 31,1\% e 28,05\%, respectivamente. Em sequência destacam-se as espécies Biblis hyperia nectanabis (Fruhstorfer, 1909) e Memphis moruus stheno (Prittwitz, 1865) na área de regeneração, ambas com frequência de $13,2 \%$, e a espécie Hamadryas februa (Hübner, [1823]) com $12 \%$ de frequência na área de mata ciliar, conforme Tabela 2 .

Tabela 2 - Número e frequência de indivíduos capturados, por espécie, na área de regeneração e na área de mata ciliar identificadas no período deste estudo

\begin{tabular}{l|c|c|c|c}
\hline \multicolumn{1}{c|}{ No de Espécies } & $\begin{array}{c}\text { Área de } \\
\text { Regeneração }\end{array}$ & $\mathrm{F}_{\mathrm{A}}(\%)$ & $\begin{array}{c}\text { Área de Mata } \\
\text { Ciliar }\end{array}$ & $\mathrm{F}_{\mathrm{A}}(\%)$ \\
\hline Hamadryas februa & 1 & 1,5 & 15 & 12,0 \\
\hline Capronnieria galesus & 18 & 26,5 & 37 & 29,6 \\
\hline Taydebis peculiaris & 26 & 38.2 & 30 & 24,0 \\
\hline Archaeoprepona chalciope & 2 & 2,9 & 4 & 3,2 \\
\hline Forsterinaria quantius & 1 & 1,5 & 7 & 5,6 \\
\hline Biblis hyperia nectanabis & 9 & 13,2 & 6 & 4,8 \\
\hline Memphis moruus stheno & 9 & 13,2 & 4 & 3,2 \\
\hline Hamadryas fornax fornax & 0 & 0,0 & 10 & 8,0 \\
\hline Eteona tisiphone & 0 & 0,0 & 2 & 1,6 \\
\hline Zaretis strigosus & 0 & 0,0 & 1 & 0,8 \\
\hline Diaethria clymena meridionalis & 0 & 0,0 & 1 & 0,8 \\
\hline Eunica margarita & 1 & 1,5 & 0 & 0,0 \\
\hline Morpho epistrophus catenaria & 0 & 0,0 & 5 & 4,0 \\
\hline Morpho helenor achillides & 0 & 0,0 & 2 & 1,6 \\
\hline Blepolenis catharinae & 1 & 1,5 & 1 & 0,8 \\
\hline Total & 68 & $100 \%$ & 125 & $100 \%$ \\
\hline Fonte: dos autores. & & & & \\
\hline
\end{tabular}

Fonte: dos autores.

Das 15 espécies obtidas na área de estudo, 14 ocorreram na área de mata ciliar e nove na área de regeneração, como demonstra o diagrama apresentado na Figura 4. Pelo índice de Shannon-Wiener obteve-se maior riqueza, diversidade e homogeneidade na área de mata ciliar, exposto na Tabela 3. 
Figura 4 - Diagrama com o número de espécies de borboletas frugívoras exclusivas e comuns aos dois ambientes (AR: área de regeneração, MC: mata ciliar), amostrados no fragmento florestal localizado no Espraiado, município de Soledade, Rio Grande do Sul

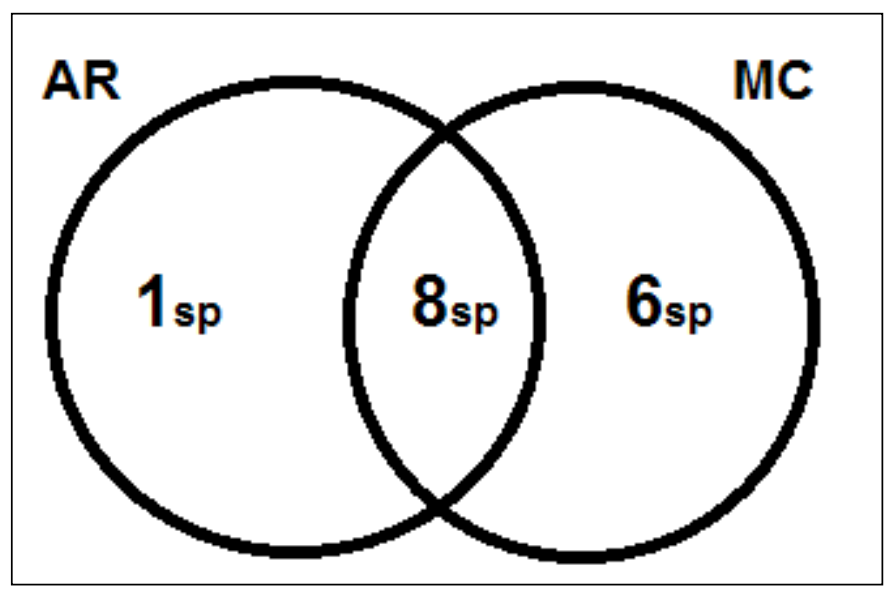

Fonte: dos autoes.

Tabela 3 - Valores obtidos pelo índice de diversidade de Shannon-Wiener nas duas áreas amostradas

\begin{tabular}{c|c|c}
\hline & Área de Mata Ciliar & Área de regeneração \\
\hline Índice de Shannon-Wiener & 0,6978 & 0,8963 \\
\hline Homogeneidade & 0,7312 & 0,7820 \\
\hline Heterogeneidade & 0,2688 & 0,2180 \\
\hline
\end{tabular}

Fonte: dos autores.

\section{DISCUSSÃO}

O bioma Mata Atlântica é considerado um dos hotspots mundiais por abrigar uma das maiores diversidades biológicas do mundo com cerca de 8.000 espécies endêmicas e por seu nível de ameaça. Por conta da localização próxima à costa sul-americana, este bioma apresenta forte influência da urbanização desenfreada, industrialização, agricultura, turismo e poluição, além de desmatamento ilegal, e inserção de espécies exóticas ao longo dos anos. Estes fatores contribuem para torná-lo o mais devastado no Brasil, restando apenas 7\% do que um dia foi e, corroborando para a gigantesca lista de espécies ameaçadas que nele vivem. (TABARELLI, 2015).

A região do presente estudo está inserida no bioma Mata Atlântica e, nesse encontrase a vegetação típica denominada Floresta Ombrófila Mista (Mata de Araucária), caracterizada por florestas com predominância de araucárias distribuídas em mosaico com grandes extensões de campos nativos de altitude, cujos limites ambientais são 
definidos por mecanismos de fogo ou balanço hídrico (QUADROS; PILLAR, 2002, BOND-BUCKUP, 2008; BOLDRINI, 2009). Devido ao impacto das atividades humanas na região, decorrente principalmente de atividades agropecuárias, atualmente a paisagem encontra-se muito fragmentada e a sua biodiversidade ameaçada (PÉRICO et al., 2005, BOND-BUCKUP, 2008).

A área de estudo possui dois locais com características estruturais diferentes, na qual a área de mata ciliar apresenta-se melhor conservada, com maior diversidade de vegetação, cobertura de copas, densidade de vegetação e menor cobertura de herbáceas quando comparada à área de regeneração. Mesmo pertencendo a um único fragmento florestal, essas diferenças estruturais influenciaram nos resultados do estudo, corroborando com Ribeiro (2006), quando salienta que se espera que as borboletas não se distribuam de maneira aleatória nos fragmentos, ocorrendo em maior densidade nas proximidades de suas plantas hospedeiras e em locais que apresentem um micro habitat mais adequado para suas atividades.

Considerando a distribuição local da fauna de borboletas, tanto a riqueza, abundância e composição das suas assembleias podem ser influenciadas por condições de heterogeneidade ambiental e influência antropogênica (TUMUHIMBISE et al., 2001, DENNIS et al., 2003, DESSUY; MORAIS 2007). As diferenças na diversidade entre habitats podem ser atribuídas à variedade de condições apropriadas para as borboletas (TUMUHIMBISE et al., 2001), o que inclui fonte de néctar, água, lama e incidência de luz solar (MURPHY; WILCOX, 1984). Além disso, a composição de espécies e a abundância relativa da comunidade de insetos podem variar ao longo do tempo por várias razões, incluindo variações climáticas e disponibilidade de alimento (WOLDA, 1988).

Obteve-se diferenças nas capturas de determinadas espécies que podem estar relacionadas a diferentes eventos, como o grau de dominância de algumas subfamílias de borboletas frugívoras, sazonalidade ou características intrínsecas de cada habitat, tais como fatores físicos e histórico de perturbação (VASCONCELOS, 2008).

A predominância de espécies de Nymphalidae obtida neste estudo é semelhante a vários trabalhos realizados no Rio Grande do Sul, como referem Marchiori e Romanowski (2006), com 36 espécies no Parque Estadual do Espinilho e 23 espécies em uma floresta de restinga no Parque Estadual de Itapuã. Quadros (2009), identificou 73 indivíduos de Nymphalidae para a Floresta Nacional de São Francisco de Paula. Iserhard et al. (2010), 108 para a Floresta Ombrófila Mista e Campos de Cima da Serra. Para a região de Floresta Ombrófila Densa e Floresta Ombrófila Mista no Rio Grande do Sul, Santos et al. (2011), registraram 8.850 indivíduos de borboletas frugívoras distribuídas em 74 espécies, utilizando também armadilhas iscadas com bananas fermentadas.

Nesse sentido, Silva (2012), descreve a região neotropical como a de maior riqueza de Satyrinae do mundo. Também, Moscoso et al., (2013) e Pedrotti et al. (2011) citam que Satyrinae é a subfamília mais rica e abundante do Rio Grande do Sul. Brown Jr. 
e Freitas (2000), afirmam que indivíduos desta subfamília respondem negativamente a perturbações antrópicas, sendo sensíveis a fragmentação, perda de habitat e poluição. Porém, Barlow et al. (2007, apud Silva, 2012) encontraram Satyrinae abundantes em plantios de eucalipto e Uehara-Prado et al. (2003) indicam ser um grupo generalista quanto a habitats.

O presente estudo obteve a mesma porcentagem de riqueza de espécies para as subfamílias Satyrinae e Biblidinae. Ribeiro (2006), também contabilizou as duas subfamílias como as mais abundantes em todos os fragmentos amostrados, mas aponta que a comunidade de borboletas frugívoras tem diversidade e composição diferente em diferentes tipos de cobertura vegetal, onde, em ambientes entre floresta e gramíneas poderiam abrigar uma maior fauna de Satyrinae e áreas de capoeira e estágios iniciais de regeneração possuem um grande número de plantas hospedeiras que são utilizadas por Biblidinae, principalmente o gênero Hamadryas.

A média da temperatura durante os quinze dias deste estudo foi de $26,5^{\circ} \mathrm{C}$ e a média pluviométrica de $57,8 \mathrm{~mm}$, resultados semelhantes são referidos por Silva et al., (2012), cujas análises das condições meteorológicas durante o seu estudo demonstraram que a temperatura média mensal teve uma forte relação com o número de indivíduos, pois registrou maior abundância entre os meses mais quentes com moderada a alta precipitação pluviométrica, Assim como nesse estudo, os períodos mais quentes do dia registraram maior atividade dos lepidópteros.

A complexidade das relações entre esses insetos e o homem e as suas interações ecológicas determinam que a sua importância biológica somente poderá ser demonstrada quando se somarem dados biológicos do ciclo de vida, inimigos naturais, plantas hospedeiras e época de ocorrência (SAVARIS; LAMPERT, 2014).

Apesar deste estudo ter sido realizado em um período relativamente curto de amostragem e a área contemplada ser pequena face a representatividade da Floresta Ombrófila Mista no Rio Grande do Sul, a guilda de borboletas frugívoras mostrouse significativa como bioindicadora da qualidade ambiental, obtendo-se maior riqueza e diversidade em ambientes melhores conservados. Também, é possível destacar a capacidade de regeneração de áreas naturais, uma vez que, oito das 15 espécies identificadas foram registradas em ambas as áreas do estudo, enfatizando a importância da conservação de fragmentos florestais.

Os inventários de diversidade são essenciais fontes de informação para a restauração, manutenção da composição, estrutura e funcionamento das comunidades naturais (BROWN; FREITAS, 2000, FREITAS et al., 2006, BOND-BUCKUP; SANTOS et al., 2008). 


\section{REFERÊNCIAS}

BELLAVER, Juliane Maria Fernandes. Efeito de borda e estrutura das comunidades de borboletas frugívoras em fragmentos de mata paludosa na planície costeira norte do Rio Grande do Sul. 2012. Dissertação (Mestrado em Biologia Animal) - Instituto de Biociências, Universidade Federal do Rio Grande do Sul, Porto Alegre, 2012.

BOLDRINI, I. I. (org.). Biodiversidade dos campos do planalto das araucárias. Brasília: MMA, 2009. 240 p.

BOND-BUCKUP, G.; DREIER, C. Desvendando a região. In: BOND-BUCKUP, G. (org.). Biodiversidade dos Campos de Cima da Serra. 1. ed. Porto Alegre: Libretos, 2008. p.11-17.

BROWN JR., K. S.; FREITAS, A. V. L. Atlantic forest butterflies: indicators for landscape conservation. Biotropica, Departamento de Zoologia, Instituto de Biologia, Universidade Estadual de Campinas, São Paulo, Brasil. v. 32, n. 4, p.934-956, 2000.

DAJOZ, Roger. Princípios de Ecologia. 7. ed. Porto Alegre: Artmed, 2005.

DENNIS, R. L. H.; SHREEVE, T. G. Toward a functional resource-based concept for a habitat: a butterfly biology viewpoint. Oikos, v. 102, n. 2, p. 417-426, 2003.

DESSUY, M.B.; MORAIS, A.B.B; Diversidade de borboletas (Lepidoptera, Papilionoideae hesperioidea) em fragmento de Floresta Estacional Decidual em Santa Maria, Rio Grande do Sul, Brasil. Revista Brasileira de Zoologia, v. 24, n. 1, p. 108-120, 2007.

FREITAS, André Victor Luca. Cores ao vento. Revista Pesquisa FAPEPS, São Paulo, n 170, p. 56-59. abril 2010.

FREITAS, A. V. L.; LEAL, I. R.; PRADO, M. H.; IANNUZZI, L. 2006. Insetos como indicadores de conservação de paisagem. In: ROCHA, C. F. D; BERGALLO, H. G.; VAN SLUYS, M.; ALVES, M. A. S.(Ed.). Biologia da conservação: essências. São Carlos: Rima, 2006, p. 357-384.

FONSECA, N. G.; KUMAGAI, A. F.; MIELKE, O. H. H. Lepidópteros visitantes florais de Stachytarpheta cayennensis(Rich.) Vahl (Verbenaceae) em remanescente de Mata Atlântica, Minas Gerais, Brasil. Revista Brasileira de Entomologia, v. 50, p. 399-405, 2006.

FURLANETI, Paula Rachel Rotta. A comunidade de borboletas frugívoras de áreas em processo de restauração, fragmentos de floresta estacional semidecidual e pastagens. 2010. Dissertação (Mestrado em Ciência Florestal) - Faculdade de Ciências Agronômicas. Universidade Estadual Paulista, Campus Botucatu, Botucatu, 2010.

ISERHARD, C.A., QUADROS, M.T., ROMANOWSKI, H.P. \& MENDONÇA Jr., M.S. 2010. Borboletas (Lep.: Papilionoidea e Hesperioidea) ocorrentes em diferentes ambientes na Floresta Ombrófila Mista e nos Campos de Cima da Serra do Rio Grande do Sul, Brasil. Biota Neotrop. 2010. v. 11. p. 361-368.

MARCHIORI, M.O.M.; ROMANOWSKI, H.P. Borboletas (Lepidoptera: Papilionoidea e Hesperioidea) do Parque Estadual do Espinilho e seu entorno, Rio Grande do Sul, Brasil.

Revista Brasileira de Zoologia, v. 23, p. 1029-1037, 2006. 
MOSCOSO, Mayana, et al. Borboletas frugívoras (Lepidoptera: Nymphalidae) do Cerro da Buena, município de Morro Redondo, RS. Disponível em: < http://cti.ufpel.edu.br/cic/ arquivos/2013/CB_01350.pdf>. Acesso em: 12 ago. 2014.

PEDROTTI, V.S. et al. Borboletas frugívoras (Lep,: Nymphalidae) ocorrentes em um fragmento de Floresta Ombrófila Mista no Rio Grande do Sul, Brasil. Biota Neotrop. 2011, 11(1): 385-390.

PETTIROSSI, Nivaldo. Riqueza, abundância e composição de espécies de borboletas frugívoras (Lepidoptera, Nymphalidae) da Reserva Florestal Mata de Santa Genebra, Campinas, Brasil. 2009. Disponível em: <http://www.museudebiologiamelloleitao. gov.br/ boletim/arquivos/25/BMBML_25_Pettirossi.pdf.> Acesso em: 05 mar. 2014.

PLANO AMBIENTAL MUNICIPAL. Disponível na Secretaria do Meio Ambiente na Prefeitura Municipal de Soledade, Rio Grande do Sul. 2008.

PLANO DE AÇÃO NACIONAL PARA A CONSERVAÇÃO DOS LEPIDÓPTEROS / Organizadores: André Victor Lucci Freitas, Onildo João Marini-Filho. - Brasília : Instituto Chico Mendes de Conservação da Biodiversidade, Icmbio, 2011. 124 p. : il. color. ; 29,7 cm. (Série Espécies Ameaçadas ; 13).

PRIMACK, Richard B.; RODRIGUES, Efraim. Biologia da conservação. Londrina: Ed. Planta, 2001. 327 p.

QUADROS, F. L. F.; PILLAR, V. P. Transições floresta-campo no Rio Grande do Sul. Ciência \& Ambiente, v. 24, p. 109-118, 2002.

QUADROS, M.T. Diversidade e composição da assembleia de borboletas (Lepidoptera: Papilionoidea e Hesperioidea) em diferentes ambientes da Floresta Nacional de São Francisco de Paula, RS. Dissertação (Mestrado em Biologia Animal). Programa de PósGraduação em Biologia Animal, Universidade Federal do Rio Grande do Sul, Porto Alegre. 2009.

RAFAEL, J.A.; MELO, G.A.R.; CARVALHO, C.J.B. de; CASARI, S.A.; CONSTANTINO R. Insetos do Brasil: Diversidade e Taxonomia. Ribeirão Preto: Holos Editora, 810 p. 2012.

RIBEIRO, Danilo Bandini. A guilda de borboletas frugívoras em uma paisagem fragmentada no alto Paraíba-SP. 2006. Dissertação (Mestrado em Ecologia) Instituto de Biologia. Universidade Estadual de Campinas, Campinas, 2006.

SANTOS, E. C.; MIELKE, O. H. H.; CASAGRANDE, M. M. Inventários de borboletas no Brasil: estado da arte e modelo de áreas prioritárias para pesquisa com vistas à conservação. Natureza \& Conservação, v. 6, n. 2, p. 68-90, 2008.

SANTOS, Jessie Pereira dos; ISERHARD, Cristiano Agra; TEIXEIRA, Melissa Oliveira; ROMANOWSKI, Helena Piccoli. Guia de borboletas frugívoras das Florestas Ombrófilas Densa e Mista do Rio Grande do Sul, Brasil. Biota Neotrop. v.11. n 3. Campinas. Jun/set 2011.

SAVARIS, M.; LAMPERT, S. Biodiversidade da Reserva Particular do Patrimônio Natural Maragato: Guia ilustrado. Passo Fundo: Ed. Universidade de Passo Fundo, 2014. 
SILVA, André Roberto Melo, et.al. Borboletas frugívoras (Lepidoptera: Nymphalidae) de uma área urbana (Área de Proteção Especial Manancial Cercadinho) em Belo Horizonte, Minas Gerais, Brasil. Biota Neotrop. v.12, n.3, Campinas. Set. 2012.

SILVA, Janaína Madruga et al. Borboletas frugívoras (Lepidoptera: Nymphalidae) no Horto Botânico Irmão Teodoro Luis, Capão do Leão, Rio Grande do Sul, Brasil. Biotemas, [S.1.], v. 26, n. 1, p. 87-95, dez. 2012. ISSN 2175-7925. Disponível em: <https://periodicos.ufsc.br/ index.php/biotemas/article/view/2175-7925.2013v26n1p87>. Acesso em: 19 Ago. 2014.

SOARES, G.R., OLIVEIRA, A.A.P de, SILVA, A.R.M. Borboletas (Lepidoptera:

Papilionoidea e Hesperioidea) de um parque urbano em Belo Horizonte, Minas Gerais, Brasil.

Biota Neotrop. v.12 n.4, Campinas Out./Dez. 2012.

TABARELLI, M.; PINTO, L. P.; SILVA, J. M. C.; HIROTA, M. M.; BEDÊ, L. C.

Desafios e oportunidades para a conservação da biodiversidade na Mata Atlântica brasileira.

Megadiversidade, v. 1, n. 1, p. 132-138, 2015.

TRIPLEHORN, Charles A.; JOHNSON, Norman F.; RIBEIRO-COSTA, Cibele S. (Rev.). Estudo dos insetos. São Paulo: Cengage Learning, 2011. 809 p.

TUMUHIMBISE, G.; OKWAKOL, M. J. N.; KANGWAGYE, T. N. Species diversity of swallowtail butterflies (Papilionidae: Lepidoptera) in North Maramagambo Forest. African Journal Ecology, v. 39, n. 1, p. 113-115, 2001.

UEHARA-PRADO, Márcio. Efeitos de Fragmentação Florestal na Guilda de Borboletas Frugívoras do Planalto Atlântico Paulista. 2003. Dissertação (Mestrado em Ecologia) Instituto de Biologia, Universidade Estadual de Campinas, Campinas, 2003.

VASCONCELOS, Rodrigo Nogueira de. Estrutura da comunidade de borboletas frugívoras em fragmentos de Floresta Atlântica e em plantações de eucalipto no extremo Sul da Bahia. 2008. Dissertação (Mestrado em Ecologia e Biomonitoramento) - Instituto de Biologia, Universidade Federal da Bahia, Salvador, 2008.

VIANA, M.V. PINHEIRO, L.A.F.V. Conservação da biodiversidade em fragmentos florestais. Série Técnica IPEF, v.12, 3225-3242p. dez. 1998.

VOLKEN, Arilson Vagner. Análise da regeneração natural da vegetação em área impactada por pedreira de granito abandonada, Viamão-RS. 2011. Dissertação (Mestrado em Avaliação de Impactos Ambientais em Mineração) - Centro Universitário La Salle, Canoas, 2011.

WWF Brasil. Disponível em: <www.wwf.org.br>. Acesso em: 05 mar. 2014. 